\title{
Safety and effectiveness of replacement with biosimilar growth hormone in adults with growth hormone deficiency: results from an international, post-marketing surveillance study (PATRO Adults)
}

\author{
Charlotte Höybye ${ }^{1} \cdot$ Paolo Beck-Peccoz ${ }^{2}$. Robert D. Murray ${ }^{3}$. Suat Simsek ${ }^{4} \cdot$ Günter Stalla ${ }^{5}$.

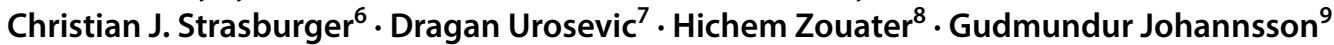

Accepted: 26 February 2021 / Published online: 20 March 2021

(c) The Author(s) 2021

\begin{abstract}
Purpose To evaluate safety and effectiveness of biosimilar recombinant human growth hormone (rhGH; Omnitrope $($ ) in adults with growth hormone deficiency (GHD), using data from the PATRO Adults study.

Methods PATRO Adults was a post-marketing surveillance study conducted in hospitals and specialized endocrinology units across Europe. The primary objective was to assess the safety of rhGH in adults treated in routine clinical practice. All adverse events (AEs) were monitored and recorded for the complete duration of Omnitrope ${ }^{\circledR}$ treatment. Effectiveness was evaluated as a secondary objective.

Results As of January 2020, 1447 patients (50.9\% male) had been enrolled from 82 centers in 9 European countries. Most patients had adult-onset GHD $(\mathrm{n}=1179 ; 81.5 \%) ; 721(49.8 \%)$ were rhGH-naïve at study entry. Overall, 1056 patients $(73.0 \%)$ reported adverse events (AEs; $n=5397$ events); the majority were mild-to-moderate in intensity. Treatment-related AEs were reported in 117 patients $(8.1 \% ; \mathrm{n}=189$ events); the most commonly reported (MedDRA preferred terms) were arthralgia $(n=19)$, myalgia $(n=16)$, headache $(n=14)$, and edema peripheral $(n=10)$. In total, 495 patients $(34.2 \%)$ had serious AEs (SAEs; $n=1131$ events); these were considered treatment-related in 28 patients ( $1.9 \% ; n=35$ events). Mean (standard deviation) IGF-I SDS increased from - $2.34(1.47)$ at baseline to - $0.23(1.65)$ at 12 months, and remained relatively stable thereafter (up to 3 years). Body mass index remained stable between baseline and 3 years.

Conclusion Data from PATRO Adults indicate biosimilar rhGH $\left(\right.$ Omnitrope $\left.^{\circledR}\right)$ is not associated with any unexpected safety signals, and is effective in adults with GHD treated in real-world clinical practice.
\end{abstract}

Keywords Adults $\cdot$ Biosimilars $\cdot$ Growth hormone $\cdot$ Growth hormone deficiency $\cdot$ Omnitrope ${ }^{\circledR}$

Hichem Zouater

hichem.zouater@sandoz.com

1 Department of Endocrinology and Department of Molecular Medicine and Surgery, Karolinska University Hospital and Karolinska Institute, Stockholm, Sweden

2 Fondazione Istituto di Ricovero e Cura a Carattere Scientifico Cà Granda Ospedale Maggiore Policlinico, Via Pietro Custodi 16, 20136 Milano, Italy

3 Leeds Centre for Diabetes \& Endocrinology, Leeds Teaching Hospitals NHS Trust, Leeds LS9 7TF, UK

4 Department of Internal Medicine/Endocrinology, Northwest Clinics Alkmaar, Wilhelminalaan 12, 1815 JD Alkmaar, The Netherlands
5 Medicover Neuroendokrinologie und Medizinische Klinik und Poliklinik IV der, Ludwig-Maximilians-Universität, Orleansplatz 3, 81667 München, Germany

6 Department of Medicine for Endocrinology, Diabetes and Nutritional Medicine, Charité Universitätsmedizin, Berlin, Germany

7 Sandoz Biopharmaceuticals, Fabrikstrasse 2, 4056 Basel, Switzerland

8 Sandoz Biopharmaceutical, c/o HEXAL AG, Industriestr. 18, 83607 Holzkirchen, Germany

9 Department of Endocrinology, Sahlgrenska University Hospital, Göteborg, Sweden 


\section{Introduction}

GH deficiency (GHD) in adults is a well-recognized condition amongst adult endocrinologists [1]. Growth hormone $(\mathrm{GH})$ is frequently the first hormone to be affected in hypothalamic-pituitary disorders, however deficiency can remain unrecognized by other specialists, which could lead to delays in referral for treatment. Adults with severe GHD may be eligible for GH replacement therapy, the main goals of which are to reverse the metabolic, functional, and psychological abnormalities associated with adult GHD [2-4]. Treatment of GHD in adults with recombinant human $\mathrm{GH}$ (rhGH) has proven to be effective for improving body composition, exercise capacity, skeletal integrity, blood lipid profile, and overall quality of life (QoL) [3, 5-7]. Clinical practice guidelines suggest that the risks associated with rhGH therapy are low [3]. However, extended clinical studies are required to confirm the long-term safety of rhGH therapy in routine clinical practice, particularly with regard to the potential diabetogenic and oncogenic risk.

Omnitrope ${ }^{\circledR}$ (somatropin) is a biosimilar rhGH approved by the European Medicines Agency in 2006, with approval granted on the basis that it matches the reference medicine (Genotropin ${ }^{\circledR}$, Pfizer) in terms of safety, efficacy, and quality. PATRO Adults is an observational, multicenter, longitudinal study of Omnitrope ${ }^{\circledR}$, conducted in hospitals and specialized endocrinology clinics across Europe. The primary objective was to assess the safety of rhGH in adults treated in routine clinical practice. Effectiveness was evaluated as a secondary endpoint [8]. Here, we present safety and effectiveness data from a snapshot analysis carried out in January 2020.

\section{Methods}

The design of the study has been reported previously [8]. Eligible patients were male or female adults who were receiving Omnitrope ${ }^{\circledR}$ treatment and who had provided informed consent. Patients who received treatment with another rhGH medicine before starting Omnitrope ${ }^{\circledR}$ therapy were also eligible for inclusion.

All adverse events (AEs) were monitored and recorded for the complete duration of Omnitrope ${ }^{\circledR}$ treatment. Particular emphasis was placed on: long-term safety; reoccurrence or de novo onset of malignancies; the incidence of hyperglycemia; and the development of glucose intolerance or diabetes. The relationship between AEs and Omnitrope ${ }^{\circledR}$ treatment was independently evaluated by investigator and sponsor assessment, and classified according to the worse case. Laboratory assessments and vital signs were requested to be documented at least once a year, according to routine clinical practice. Effectiveness assessments included analysis of IGF-I levels, anthropometric measures and lipids.

\section{Data collection/analysis and study populations}

Patient data were entered into an electronic case report form (eCRF) at each routine visit. eCRFs were reviewed by data management and on-site monitoring was performed by a contract research organization. Standard descriptive statistics (mean, standard deviation, and frequency) were used to describe continuous parameters (e.g. age, height, weight) and categorical parameters (e.g. gender); median and range were used to describe parameters (e.g. treatment duration) that are not normally distributed.

The safety population consisted of all patients documented within the eCRF at the time of the analysis cut-off date (January 31, 2020). Patients for whom neither a visit date nor a start date of Omnitrope ${ }^{\circledR}$ treatment had been documented were not included. The effectiveness population was a subset of the safety set and consisted of all patients with a documented baseline visit (start of Omnitrope ${ }^{\circledR}$ treatment) and at least one documented visit under Omnitrope ${ }^{\circledR}$ treatment with the corresponding dates.

\section{Results}

\section{Patient characteristics and diagnostic details}

As of January 2020, 1447 patients (50.9\% male) had been enrolled from 82 centers in 9 European countries (Czech Republic [ $n=9$; all rhGH-naïve], France $[n=95$; rhGHnaïve, $n=45$; pre-treated, $n=50]$, Germany $[\mathrm{n}=388$; rhGH-naïve, $n=218$; pre-treated, $n=170]$, Greece $[n=5$; all rhGH-naïve], Italy [ $\mathrm{n}=99$; rhGH-naïve, $\mathrm{n}=61$; pretreated, $n=38]$, Netherlands $[n=60$; rhGH-naïve, $n=26$; pre-treated, $n=34]$, Spain $[n=48$; rhGH-naïve, $n=13$; pretreated, $n=35]$, Sweden [ $n=303$; rhGH-naïve, $n=135$; pretreated, $n=168$ ], UK [ $n=440$; rhGH-naïve, $n=209$; pretreated, $\mathrm{n}=231])$. At the time of the analysis, 981 patients (67.8\%) were active in the study and 466 (32.2\%) had discontinued the study. Most patients had adult-onset GHD $(\mathrm{n}=1179,81.5 \%$; childhood-onset, $\mathrm{n}=251,17.3 \%$; missing, $\mathrm{n}=17,1.2 \%)$. Also, 721 patients $(49.8 \%)$ were rhGH-naïve at study entry (adult-onset GHD, $\mathrm{n}=669$; childhood-onset GHD, $n=42$; missing, $n=10)$ while $726(50.2 \%)$ had been pre-treated with another rhGH.

Further characteristics of enrolled patients are shown in Table 1. Overall, 1267 (99.7\%) of patients with combined GHD $(n=1271)$ had additional pituitary hormone 
Table 1 Patient characteristics at enrollment

\begin{tabular}{|c|c|c|c|c|c|c|c|c|}
\hline & \multirow[t]{2}{*}{ Total, n } & \multicolumn{2}{|l|}{ Gender } & \multicolumn{3}{|l|}{ GHD onset } & \multirow{2}{*}{$\begin{array}{l}\text { Mean (SD) age, } \\
\text { years }\end{array}$} & \multirow{2}{*}{$\begin{array}{l}\text { Mean (SD) } \\
\text { BMI, kg/ } \\
\mathrm{m}^{2}\end{array}$} \\
\hline & & Male, $\mathrm{n}(\%)$ & Female, n (\%) & Childhood, n (\%) & Adulthood, n (\%) & Missing, n (\%) & & \\
\hline Isolated GHD & 165 & $71(43.0)$ & $94(57.0)$ & 34 (20.6) & $126(76.4)$ & $5(3.0)$ & $43.3(15.2)$ & $29.6(7.0)$ \\
\hline MPHD & 1271 & $659(51.8)$ & $612(48.2)$ & $213(16.8)$ & $1049(82.5)$ & $9(0.7)$ & $49.2(15.5)$ & $29.5(6.4)$ \\
\hline Other & 11 & $7(63.6)$ & $4(36.4)$ & $4(36.4)$ & $4(36.4)$ & $3(27.3)$ & $39.6(15.6)$ & $28.3(4.4)$ \\
\hline Total & 1447 & 737 (50.9) & $710(49.1)$ & $251(17.3)$ & 1179 (81.5) & $17(1.2)$ & $48.5(15.6)$ & $29.5(6.5)$ \\
\hline
\end{tabular}

$B M I$ body mass index, $G H D$ growth hormone deficiency, $M P H D$ multiple pituitary hormone deficiency, $S D$ standard deviation

deficiencies (one additional hormone deficiency, $\mathrm{n}=228$ [17.9\%]; 2 additional deficiencies, $\mathrm{n}=326$ [25.6\%]; 3 additional deficiencies, $\mathrm{n}=552$ [43.4\%]; 4 additional deficiencies, $\mathrm{n}=161[12.7 \%])$. Concomitant medication use included thyroid hormones (any; $\mathrm{n}=907$ ), hydrocortisone/cortisone (any; $\mathrm{n}=799$ ), sex hormones (any; $\mathrm{n}=593$ ), and desmopres$\sin ($ any; $\mathrm{n}=73$ ).

\section{rhGH treatment}

The overall mean (SD) baseline Omnitrope ${ }^{\circledR}$ dose was 0.292 $(0.238) \mathrm{mg} /$ day $(0.276$ [0.234] mg/day and 0.309 [0.242] $\mathrm{mg}$ /day in males and females, respectively). Among rhGHnaïve patients, the mean (SD) baseline dose was $0.204(0.14)$ $\mathrm{mg} /$ day; in pre-treated patients, it was $0.379(0.28) \mathrm{mg} / \mathrm{day}$. At the time of the analysis, the median (range) Omnitrope ${ }^{\circledR}$ treatment duration in the study was $45.3(0.0-150)$ months (approx. 3.8 years).

\section{Treatment discontinuation}

As of January 2020, 466 patients had discontinued the study. The most commonly recorded reasons for discontinuation were: 'other', $\mathrm{n}=150 ; \mathrm{AE}, \mathrm{n}=101$; patients not wishing to continue the injections, $n=96$; lost to follow-up, $n=49$. The most common AEs that resulted in discontinuation (MedDRA preferred term) were headache $(\mathrm{n}=7)$, neoplasm progression $(n=6)$, prostate cancer $(n=6)$, arthralgia $(n=5)$, myalgia $(n=3)$, pain in extremity $(n=3)$, edema $(n=3)$, pneumonia $(n=3)$, and sepsis $(n=3)$. AEs of special interest that led to discontinuation (MedDRA system organ class [SOC]) included 'Neoplasms benign, malignant, and unspecified' $(\mathrm{n}=39)$ and 'Metabolism and nutrition disorders' ( $\mathrm{n}=4$, including diabetes mellitus/type 2 diabetes $[\mathrm{n}=3])$.

\section{Adverse events}

A summary of reported AEs is shown in Table 2. Overall, 1056 patients $(73.0 \%)$ reported AEs $(n=5397$ events), the majority of which were considered to be mild or moderate
Table 2 Summary of adverse events

\begin{tabular}{|c|c|c|c|}
\hline \multirow[t]{2}{*}{ Total number of patients, $\mathrm{N}=1447$} & \multicolumn{2}{|c|}{ Patients } & \multirow[t]{2}{*}{ AEs, $n$} \\
\hline & $\mathrm{n}$ & $\%$ & \\
\hline Any AE & 1056 & 73.0 & 5397 \\
\hline \multicolumn{4}{|l|}{ Relationship to study drug } \\
\hline Not suspected & 1014 & 70.1 & 5205 \\
\hline Suspected & 117 & 8.1 & 189 \\
\hline Missing/not assessable & 3 & 0.2 & 2 \\
\hline \multicolumn{4}{|l|}{ Intensity } \\
\hline Mild & 858 & 59.3 & 3502 \\
\hline Moderate & 587 & 40.6 & 1414 \\
\hline Severe & 171 & 11.8 & 302 \\
\hline Missing & 66 & 4.6 & 179 \\
\hline \multicolumn{4}{|l|}{ Changes to rhGH treatment } \\
\hline Not changed & 987 & 68.2 & 5016 \\
\hline Increased & 28 & 1.9 & 38 \\
\hline Reduced & 65 & 4.5 & 103 \\
\hline Interrupted & 62 & 4.3 & 90 \\
\hline Permanently discontinued & 100 & 6.9 & 139 \\
\hline Missing & 7 & 0.5 & 11 \\
\hline \multicolumn{4}{|l|}{ SAEs } \\
\hline No & 969 & 67.0 & 4264 \\
\hline Yes & 495 & 34.2 & 1131 \\
\hline Missing & 2 & 0.1 & 2 \\
\hline \multicolumn{4}{|l|}{ SAE relationship to study drug } \\
\hline Not suspected & 477 & 33.0 & 1096 \\
\hline Suspected & 28 & 1.9 & 35 \\
\hline
\end{tabular}

$A E$ adverse event, $r h G H$ recombinant human growth hormone, $S A E$ serious adverse event

in intensity. AEs considered to be related to treatment were reported in 117 patients $(8.1 \% ; \mathrm{n}=189$ events). The most commonly reported treatment-related AEs (MedDRA preferred terms) were: arthralgia $(n=19)$, myalgia $(n=16)$, headache $(n=14)$, and edema peripheral $(n=10)$.

Overall, 39 events of confirmed diabetes mellitus (MedDRA high-level term: Diabetes [including subgroups]) were reported in 37 patients; 32 events (in 30 patients) were newly diagnosed, and 7 events (in 7 patients) were worsening or 
inadequately controlled diabetes mellitus. Among these 37 patients, $22(59.5 \%)$ had received concomitant statin therapy and $28(75.7 \%)$ had received corticosteroids.

A total of 69 events of malignancies were reported in 60 patients. These events were documented under the SOC 'Neoplasms benign, malignant, and unspecified' and classified via medical review as being malignant. Sixty events (in 51 patients) were newly diagnosed; the most common (by MedDRA preferred term) were basal cell carcinoma (13 events in 12 patients), prostate cancer ( 9 events in 9 patients), malignant melanoma (5 events in 5 patients), and breast cancer ( 3 events in 3 patients).

In total, 495 patients $(34.2 \%)$ had SAEs $(n=1131$ events); of these, 28 patients $(1.9 \%)$ had SAEs that were considered to be treatment-related ( $\mathrm{n}=35$ events). The most commonly recorded treatment-related SAEs (MedDRA preferred terms) were diabetes mellitus/type 2 diabetes mellitus $(n=6)$, lipoma $(n=2)$, and neoplasm progression $(n=2)$. Fatal AEs were recorded in 27 patients, the most common being cardiac disorders $(n=10)$ and cancer $(n=8)$.

\section{Effectiveness}

Data for effectiveness parameters are presented for patients who were rhGH-naïve on study entry. Mean (SD) IGF-I SDS increased from - 2.34 (1.47) at baseline to - 0.23 (1.65) at 12 months, and remained relatively stable thereafter (up to 36 months; Fig. 1). After 6 months, lean body mass increased by approximately $6 \%$ compared with baseline; the increase after 3 years was approximately $4 \%$ (Fig. 2a). Total fat mass also improved within the first year of treatment, decreasing by approximately $9 \%$ at 12 months, before returning to baseline levels at 36 months (Fig. 2b). BMI remained stable between baseline and 3 years (Fig. 2c).
Lipid profile improved over time with rhGH treatment. This is exemplified by the decrease in mean (SD) TC/HDL ratio over time, from 4.49 (1.42) at baseline to 4.28 (1.45) after 3 years (Fig. 3).

\section{Discussion}

The PATRO Adults post-marketing surveillance study will provide data on the long-term safety and effectiveness of Omnitrope ${ }^{\circledR}$ treatment in adult patients with GHD in a reallife clinical setting. Based on the current analysis, there have so far been no unexpected safety signals, and treatment is effective (in rhGH-naïve patients).

AEs reported in the current analysis included 32 cases of new-onset diabetes mellitus (in 30 patients) and 7 cases of worsening of pre-existing diabetes mellitus. A previous evaluation of data from PATRO Adults (data cut-off July 2018) examined the impact of rhGH on glucose metabolism and onset of diabetes mellitus [9]. No signals of an increased risk of diabetes mellitus and glucose metabolism disorders were reported, consistent with the experience with other rhGH treatments [10-12]. A review of data from largescale registry studies of GH replacement therapy suggested that the incidence of diabetes mellitus may only be slightly increased in patients with pre-existing risk factors for diabetes mellitus, and not as a result of rhGH therapy [13].

The current analysis also includes 69 reports of malignancy events (in 60 patients). The occurrence of on-study malignancies in PATRO Adults has been reported previously (based on data from July 2018) [14]. While the data did not in general support a carcinogenic effect of rhGH in adults with GHD, an increased risk of second new malignancies in patients with previous cancer could not be excluded. Again, this is consistent
Fig. 1 Insulin-like growth factor (IGF)-I SDS over time in rhGH-naïve patients (effectiveness population). The grey shaded area represents the IGF-I target range. $r h G H$ recombinant human growth hormone

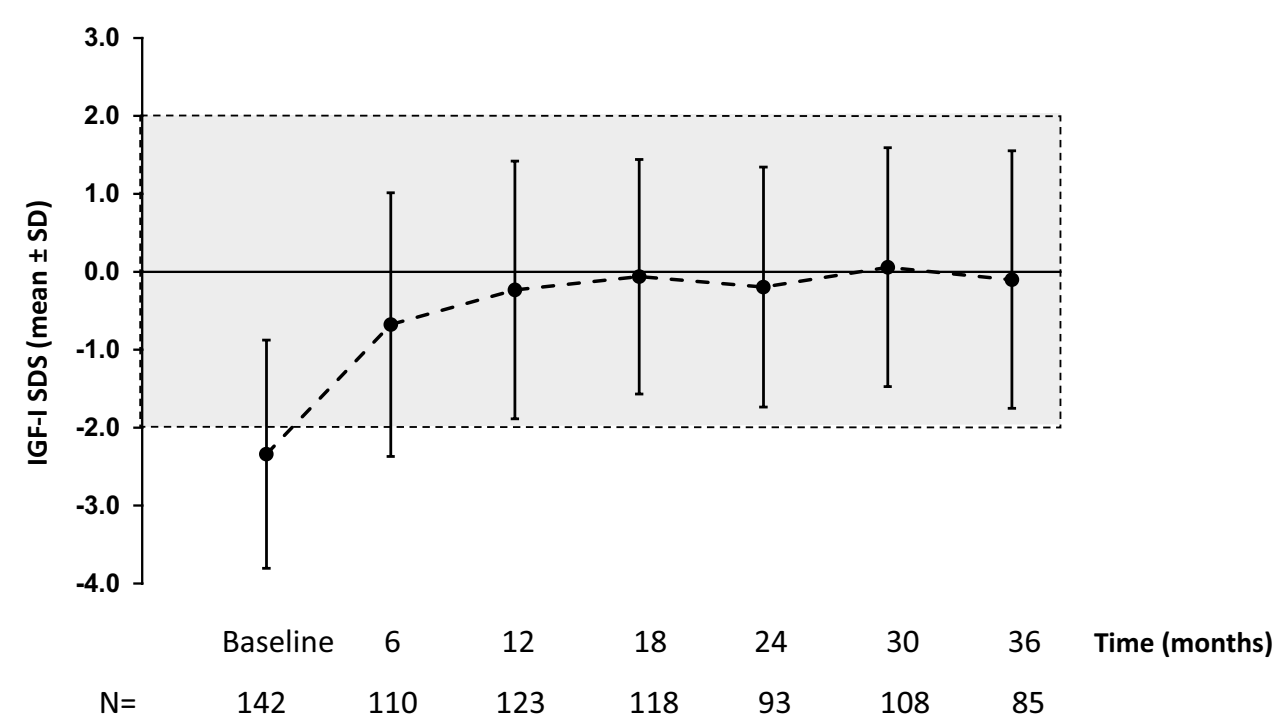


Fig. 2 Lean body mass (LBM; a), total fat mass (b), and body mass index (BMI; c) over time in rhGH-naïve patients (effectiveness population). $r h G H$ recombinant human growth hormone

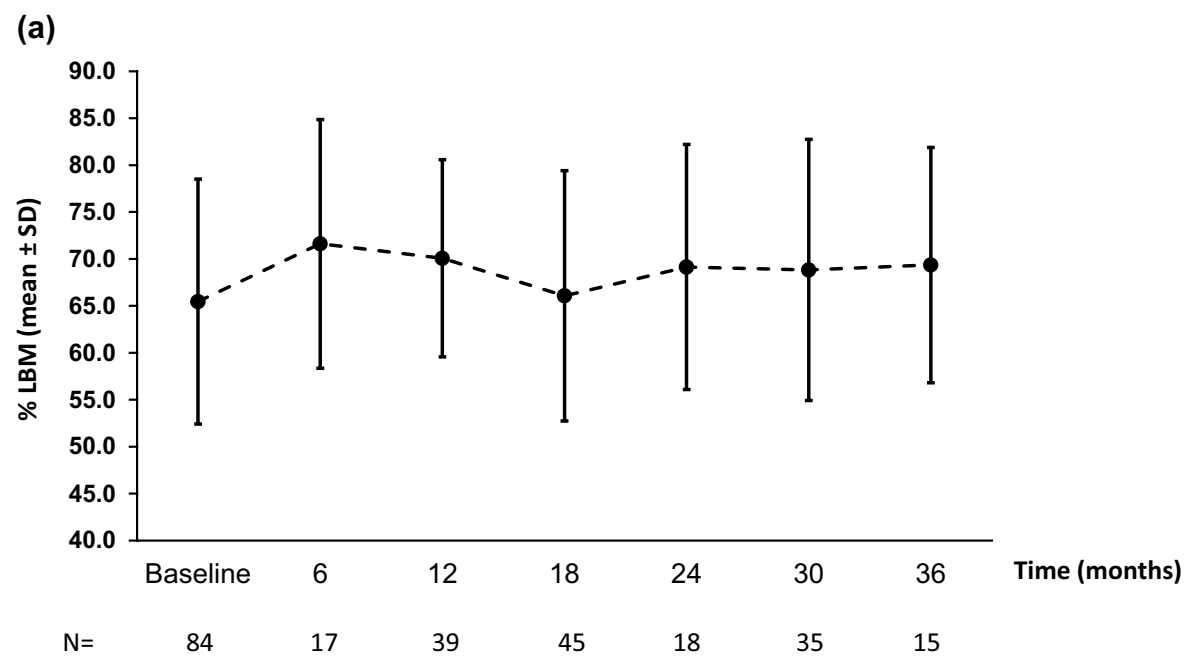

(b)

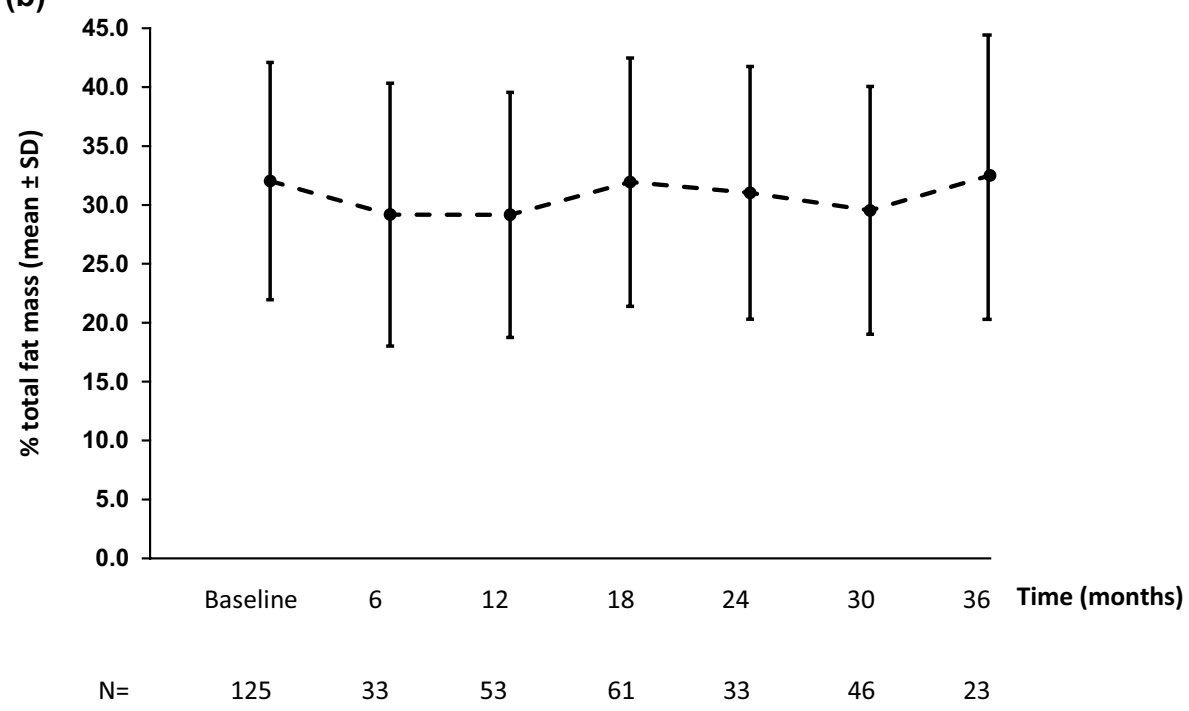

(c)

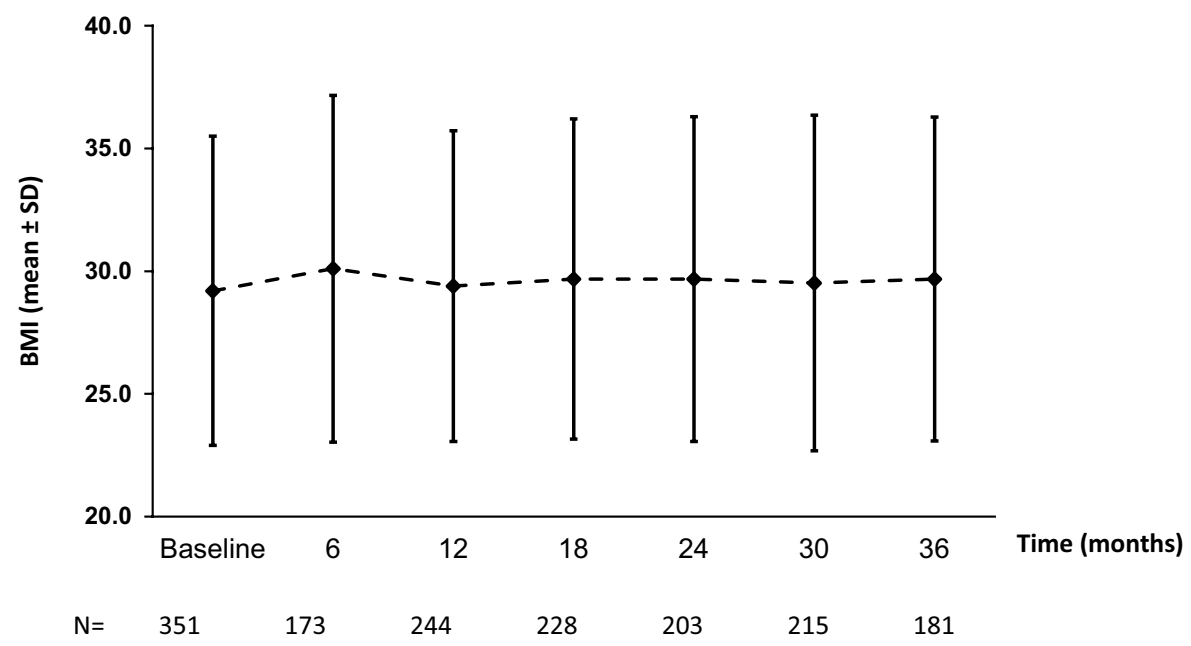


Fig. 3 Change in total cholesterol/high-density cholesterol (TC/HDL) over time in rhGHnaïve patients (effectiveness population). rhGH recombinant human growth hormone

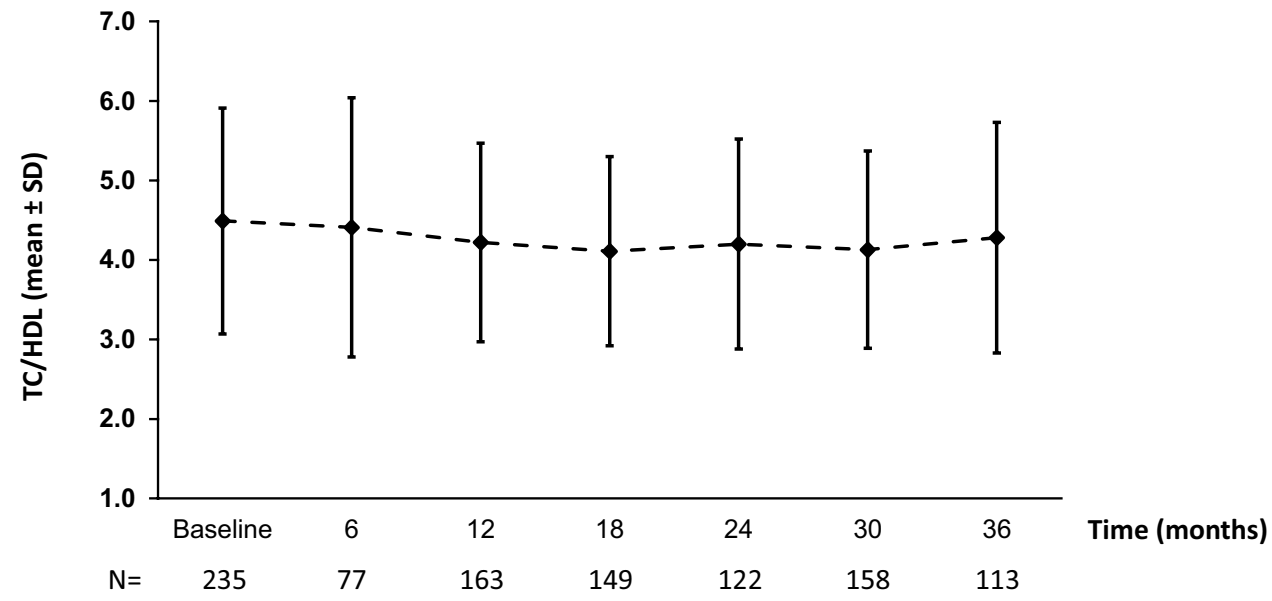

with previous data reported for $\mathrm{rhH}$ medicines in this setting $[13,15]$.

A number of benefits of rhGH therapy in adult GHD have been previously reported, including improvements in body composition, exercise capacity, skeletal integrity, blood lipid profile, and QoL $[3,16]$. The data presented here suggest modest improvements in body composition and blood lipid profile with Omnitrope ${ }^{\circledR}$ treatment (albeit data are included only for patients who were rhGH-naïve on study entry), consistent with previous reports.

It should be highlighted that the PATRO Adults study has several limitations, some of which are common to all observational studies. These include a potential for selection bias due to the inclusion of selected clinics and enrollment of patients from only these clinics. Also, as study data is collected according to routine clinical practice, there is no regular visit schedule, information bias is a possibility (as a result of incorrect or inexact recording), and different techniques may be used to measure the same parameter. Furthermore, there may be under-reporting of AEs because of the extended time periods between patient visits in the study (6-12 months) and restricted consultation time during visits. The relatively small sample size/data sets for some parameters is also a potential limitation and may hinder the interpretation of certain data. Another drawback is the possibility of missing out on useful information due to the set-up of the eCRF. For example, in the present study, the option to select 'other' as a reason for study discontinuation resulted in loss of potentially useful data for 150 participants. In the future, avoiding use of general data entry options such as 'other' may improve the quality of data collected from such observational studies.

\section{Conclusion}

In summary, data so far from PATRO Adults indicate biosimilar rhGH (Omnitrope ${ }^{\circledR}$ ) is not associated with any unexpected safety signals, and is effective in adults with GHD treated in real-world clinical practice. However, continued follow-up of adult GHD patients during rhGH therapy and after treatment termination is necessary, to ensure long-term safety.

Acknowledgements The authors thank Yu-Ming Shen (Sandoz/Hexal AG) for providing statistical support. The authors thank all patients and investigators who participated in the PATRO Adults study. Medical writing support was provided by Tony Reardon of Aura, a division of Spirit Medical Communications Group Ltd, supported by Sandoz/ Hexal AG.

Author contributions All authors contributed to data interpretation, writing and review of the manuscript, and approved the final version of the manuscript for publication.

Funding The PATRO Adults study is funded by Sandoz/Hexal AG. Medical writing support was funded by Sandoz/Hexal AG.

Data availability The datasets generated during and/or analyzed during the current study are not publicly available as the study is still ongoing, but are available from the corresponding author on reasonable request.

\section{Declarations}

Conflict of interest $\mathrm{CH}$ has acted as an investigator for Sandoz, Pfizer, and NovoNordisk; has received lecture fees from Sandoz, Pfizer, and NovoNordisk; and is a member of the global steering committee for the PATRO Adults study. RDM has received research funding from San- 
doz, Ipsen, and Pfizer; has received lecture fees from Pfizer; and is a member of the global steering committee for the PATRO Adults study. PBP and SS are members of the global steering committee for the PATRO Adults study. GS has received honoraria for scientific advisory work and/or reimbursement of delegate fees for congresses/seminars and/or travel costs and/or research grants from the HRA, Ipsen, Lilly, Novartis, NovoNordisk, Pfizer, Sandoz, and Shire; and is a member of the global steering committee for the PATRO Adults study. CJS is a member of the German PATRO advisory board, and has received advisory honoraria or speaker fees from Sandoz, NovoNordisk, Ipsen, Ascendis, and Pfizer. GJ has served as a consultant for Novo Nordisk, Shire, and AstraZeneca, and has received lecture fees from Eli Lilly, Ipsen, Novartis, Novo Nordisk, Merck Serono, Otsuka, and Pfizer. DU and HM are employees of Sandoz.

Ethical approval The PATRO Adults study protocol was approved by the ethics review committee of all participating centers in accordance with national laws and regulations. Written informed consent was obtained from all participating patients. The study was approved by the following ethics committees: Czech Republic: Etická komise Všeobecné fakultní nemocnice v Praze, 12808 Praha 2; Multicentrická etická komise Fakultní nemocnice Hradec Králové, 50005 Hradec Králové. Germany: Medical Council of Bavaria Ethics Committee, 81677 München; Medical Council of Hamburg Ethics Committee, 22083 Hamburg; Medical Council of Saxony Ethics Committee, 01099 Dresden; Medical Council of Thuringia Ethics Committee, 07751 Jena; Ärztekammer Hessen, 60488 Frankfurt am Main; Medical Council of Lower Saxony Ethics Committee, 30175 Hannover; Medical Faculty of University of Hannover Ethics Committee, 30625 Hannover; Medical Faculty of University of Würzburg Ethics Committee, 97078 Würzburg; Medical Faculty of University of Tübingen Ethics Committee, 72074 Tübingen; Medical Faculty of University of Erlangen Ethics Committee, 91054 Erlangen; Medical Council of Westphalia-Lippe Ethics Committee, 48147 Münster; Medical Council of Baden-Wurttemberg Ethics Committee, 70597 Stuttgart; Medical Faculty of University of Aachen Ethics Committee, 52074 Aachen; Medical Council of Berlin Ethics Committee, 10707 Berlin; Ethikkommission an der Medizinischen Fakultät der Universität Leipzig, 04109 Leipzig, Germany; Medical Faculty of Ludwig-Maximilian University Munich Ethics Committee, 80336 Munich; Bayerische Landesärztekammer, 81677 München. Spain: Comité de Ética de Investigación de los Hospitales Universitarios Virgen Macarena-Virgen del Rocio, 41013 Sevilla; Comité Ético de Investigación Clínica Hospital Universitari Vall d'Hebron, 08035 Barcelona. UK: NRES Committee South Central-Southampton A, Bristol BS1 2NT. Italy: Comitato di Etica Della Fondazione Irccs ca' Granda Ospedale Maggiore, 20122 MILANO; Comitato Etico Dell'Azienda Ospedaliera Universitaria S. Martino Di Genova, 16132 GENOVA; Comitato Etico Dell'Azienda Ospedaliera Universitaria S. Giovanni Battista Di Torino, 10126 TORINO; Comitato Etico di Area Vasta Emilia Centro (CE-AVEC) c/o Ufficio Ricerca e Innovazione, Azienda Ospedaliero Universitaria di Ferrara, 44121 FERRARA; Comitato Etico Delle Aziende Sanitarie Dell'Umbria; Segreteria Scientifico Amministrativa, 06073 PERUGIA; Comitato Etico per le attività biomediche "Carlo Romano", dell'Università degli Studi di Napoli Federico II, Segreteria tecnicoscientifica, 80131 NAPOLI; Comitato Etico Dell'Azienda OspedalieroUniversitaria Ospedali Riuniti Umberto I-G.M. Lancisi-G. Salesi Di Ancona, 60126 ANCONA; Comitato Etico Per La Sperimentazione Dell'Azienda Ospedaliera Di Padova, 35128 PADOVA. The Netherlands: METC Isala, 8000 GK Zwolle; Wetenschapsbureau, 1815 GM Alkmaar. Sweden: Regionala Etikprövningsnämnden i Stockholm, 17177 Stockholm. France: Institut National des Données de Santé, 94220 Charenton-le-Pont; Comité Consultatif pour le Traitement de l'Information en matière de Recherche pour la Santé, 75231 Paris cedex 05 .
Consent for publication As part of the informed consent process, all patients provided written consent for the publication of data collected in the study.

Open Access This article is licensed under a Creative Commons Attribution 4.0 International License, which permits use, sharing, adaptation, distribution and reproduction in any medium or format, as long as you give appropriate credit to the original author(s) and the source, provide a link to the Creative Commons licence, and indicate if changes were made. The images or other third party material in this article are included in the article's Creative Commons licence, unless indicated otherwise in a credit line to the material. If material is not included in the article's Creative Commons licence and your intended use is not permitted by statutory regulation or exceeds the permitted use, you will need to obtain permission directly from the copyright holder. To view a copy of this licence, visit http://creativecommons.org/licenses/by/4.0/.

\section{References}

1. Melmed S (2019) Pathogenesis and diagnosis of growth hormone deficiency in adults. N Engl J Med 380(26):2551-2562

2. Ho KK, for the GH Deficiency Consensus Workshop Participants (2007) Consensus guidelines for the diagnosis and treatment of adults with GH deficiency II: a statement of the GH Research Society in association with the European Society for Pediatric Endocrinology, Lawson Wilkins Society, European Society of Endocrinology, Japan Endocrine Society, and Endocrine Society of Australia. Eur J Endocrinol 157(6):695-700. https://doi.org/10. 1530/EJE-07-0631

3. Molitch ME, Clemmons DR, Malozowski S, Merriam GR, Vance ML, Endocrine Society (2011) Evaluation and treatment of adult growth hormone deficiency: an Endocrine Society clinical practice guideline. J Clin Endocrinol Metab 96(6):1587-1609. https:// doi.org/10.1210/jc.2011-0179

4. Kargi AY, Merriam GR (2013) Diagnosis and treatment of growth hormone deficiency in adults. Nat Rev Endocrinol 9(6):335-345

5. Bex M, Abs R, Maiter D, Beckers A, Lamberigts G, Bouillon $R$ (2002) The effects of growth hormone replacement therapy on bone metabolism in adult-onset growth hormone deficiency: a 2-year open randomized controlled multicenter trial. J Bone Miner Res 17(6):1081-1094. https://doi.org/10.1359/jbmr.2002. 17.6.1081

6. Elbornsson M, Götherström G, Bosæus I, Bengtsson BÅ, Johannsson G, Svensson J (2013) Fifteen years of GH replacement improves body composition and cardiovascular risk factors. Eur J Endocrinol 168(5):745-753. https://doi.org/10.1530/EJE-12-1083

7. Elbornsson M, Horvath A, Götherström G, Bengtsson BA, Johannsson G, Svensson J (2017) Seven years of growth hormone $(\mathrm{GH})$ replacement improves quality of life in hypopituitary patients with adult-onset GH deficiency. Eur J Endocrinol 176(2):99-109. https://doi.org/10.1530/EJE-16-0875

8. Beck-Peccoz P, Minuto F, Leal-Cerro A, Zabransky M, Stalla G (2012) Rationale and design of PATRO Adults, a multicentre, noninterventional study of the long-term efficacy and safety of Omnitrope $^{\circledR}$ for the treatment of adult patients with growth hormone deficiency. Ther Adv Endocrinol Metab 3(3):85-91. https:// doi.org/10.1177/2042018812444152

9. Beck-Peccoz P, Höybye C, Murray RD, Simsek S, Zabransky M, Zouater H, Stalla G (2019) No increased risk of glucose metabolism disorders in adults with growth hormone deficiency undergoing long-term treatment with biosimilar somatropin (Omnitrope $\left.{ }^{\circledR}\right)$ : 
data from an observational, longitudinal study. BMC Endocr Disord 19(1):138. https://doi.org/10.1186/s12902-019-0464-2

10. Luger A, Mattsson AF, Koltowska-Häggström M, Thunander M, Góth M, Verhelst J, Abs R (2012) Incidence of diabetes mellitus and evolution of glucose parameters in growth hormone-deficient subjects during growth hormone replacement therapy: a long-term observational study. Diabetes Care 35(1):57-62. https://doi.org/ $10.2337 / \mathrm{dc} 11-0449$

11. Attanasio AF, Jung H, Mo D, Chanson P, Bouillon R, Ho KK, Lamberts SW, Clemmons DR, HypoCCS International Advisory Board (2011) Prevalence and incidence of diabetes mellitus in adult patients on growth hormone replacement for growth hormone deficiency: a surveillance database analysis. J Clin Endocrinol Metab 96(7):2255-2261. https://doi.org/10.1210/jc. 2011-0448

12. Weber MM, Biller BM, Pedersen BT, Pournara E, Christiansen JS, Höybye C (2017) The effect of growth hormone $(\mathrm{GH})$ replacement on blood glucose homeostasis in adult nondiabetic patients with GH deficiency: real-life data from the NordiNet ${ }^{\circledR}$ International Outcome Study. Clin Endocrinol (Oxf) 86(2):192-198. https:// doi.org/10.1111/cen.13256

13. Stochholm K, Kiess W (2018) Long-term safety of growth hormone-a combined registry analysis. Clin Endocrinol (Oxf) 88(4):515-528. https://doi.org/10.1111/cen.13502
14. Beck-Peccoz P, Höybye C, Murray RD, Simsek S, Zabransky M, Zouater H, Stalla G (2020) Malignancy risk in adults with growth hormone deficiency undergoing long-term treatment with biosimilar somatropin (Omnitrope ${ }^{\circledR}$ ): data from the PATRO Adults study. Ther Adv Endocrinol Metab 11:2042018820943377. https://doi. org/10.1177/2042018820943377

15. Krzyzanowska-Mittermayer K, Mattsson AF, Maiter D, FeldtRasmussen U, Camacho-Hübner C, Luger A, Abs R (2018) New neoplasm during $\mathrm{GH}$ replacement in adults with pituitary deficiency following malignancy: a KIMS analysis. J Clin Endocrinol Metab 103(2):523-531. https://doi.org/10.1210/jc.2017-01899

16. Höybye C, Burman P, Feldt-Rasmussen U, Hey-Hadavi J, Aydin F, Camacho-Hubner C, Mattsson AF (2019) Change in baseline characeristics over 20 years of adults with growth hormone (GH) deficiency on GH rplacement therapy. Eur J Endocrinol 181(6):629-638. https://doi.org/10.1530/EJE-19-0576

Publisher's Note Springer Nature remains neutral with regard to jurisdictional claims in published maps and institutional affiliations. 